\title{
THE CORRELATION AND INTERACTION OF THE SUSTAINABILITY AND GLOBAL INNOVATION IN TRANSITION COUNTRIES
}

\author{
Milenkovic, N. ${ }^{1 *}$ - Cogoljevic, M. $^{2}$ - Jovanovic, D. ${ }^{1}$ - Petrovic, ${ }^{3}{ }^{3}-$ Stankovic, M. ${ }^{1}$ \\ ${ }^{1}$ School of Economics and Management Studies, Karadjordjeva 52, 34000 Kragujevac, Serbia \\ (phone: +381 (034) 356 569) \\ ${ }^{2}$ Faculty of Business Economics and Entrepreneurship, Mitropolita Petra 8 \\ 11000 Belgrade, Serbia \\ (phone: +381 (011) 2762 194)
}

${ }^{3}$ Faculty of entrepreneurial business and management of real estate, University of Uninon Nikola Tesla, Cara Dušana 62-64, 11000 Belgrade, Serbia

(phone: +381 (011) 2180143 )

*Corresponding author

e-mail: nmilenkovic644@gmail.com

(Received $14^{\text {th }}$ Oct 2018; accepted $5^{\text {th }}$ Dec 2018)

\begin{abstract}
In the last decade, the question of the current disproportion of quality of life and economic progress of global proportions is often raised, in contemporary socio-economic and political-economic conditions. We are witnessing a constant tendency toward targeted well-being that can be seen through human, economic and environmental benefits. The first two dimensions are goals that imply the complete sustainability of social protection of people and the protection of the environment. They are in a strong correlation with each other, since they can not be regarded as separate goals, but mutually equal because they depend on each other. On the other hand, in order to achieve sustainability of economic well-being, it is necessary to include multidimensional aspects of innovation, which will provide tools, through which adjustments of policies to promote long-term growth of production and increase of productivity, ie decrease of unemployment rate, will be adapted. Therefore, as part of the globalization process, it is necessary to review the possibilities and capacities of efficient sustainability of people's quality of life and environmental protection, with constant and balanced economic prosperity, not only countries in transition, but all factors in the world economy.
\end{abstract}

Keywords: quality, continuial, novelty, worldwide, guide

\section{Introduction}

If the "sustainability index" can be taken as a genetic term, then it would include two of the most important aspects of quality of life, or a sustainability indicator. These indicators are:

- Sustainable Society Index (SSI) and

- Environmental Performance Index (EPI).

Twenty-four indicators are taken into account when determining the index of a sustainable society. They are divided into seven categories, and those in three dimensions (living standard of the population, environmental protection and economic well-being). By summing up the data obtained through these dimensions, the SSI is calculated. This index is used to monitor the prosperity of the country's determination, the establishment and determination of sustainability priorities, the comparison of achieved results at the level of countries and regions, and for further research and 
development. What is characteristic of this type of indicator, and based on previous research, is that high-income countries per capita at an annual level have a high standard of living but do not achieve such good results when it comes to environmental protection. There is a trend of improving living standards and economic well-being on a global level, while environmental protection is accompanied by a negative index, despite all plans and signed interstate agreements (Van de Kerk et al., 2008).

Although it can be said that, in general, progress has been made, it is disturbing that it is not balanced between the three dimensions of society's sustainability, and that there are differences in development between high and low income countries. Particularly disappointing are the still low results of organic agriculture, renewable energy and energy savings.

With the UN's sustainable development goals in 2018, the emphasis on the actions of the governments of countries that are subject to this type of indexing is on explaining the achieved results through a series of pollution control and challenges to natural resource management in relation to quantitative indicators. Precisely obtained data and empirical approach to environmental issues provide the possibility for a certain type of security in identifying problems, monitoring trends, highlighting the results of the current policy action, identifying best practices, and optimizing the benefits of environmental investments (Yale Univeristy, 2018).

The aforementioned empirical approach to environmental issues works through several instruments, and one of them is the environmental efficiency index. The EPI is a joint project developed by the Yale Center for Environmental Law \& Policy (YCELP) and the Center for International Earth Science Information Network (CIESIN) at Columbia University, in collaboration with the Samuel Family Foundation and the World Economic Forum (Hsu et al., 2014).

Based on the index value obtained, countries are ranked, and an assessment is made of the success of meeting the set objectives for the improvement of environmental protection for each of them. In this way, the best applied approach to problem-solving is considered, and guidance is provided to countries with a tendency towards further progress.

The EPI offers the possibility of bridging the two opposing sides - environmental health, which increases economic growth and prosperity, and the vitality of the ecosystem, under the pressure of industrialization and urbanization. Strategic management is a critical and essential factor necessary to establish a balance between these two dimensions of sustainability.

With the aim of a comprehensive approach to innovation in the economy and the provision of instruments that help achieve the desired economic goals, the Global Innovation Index contributes to the creation of an environment in which innovative factors are continually valued.

The core of the GII report consists of ranking innovative capabilities and innovation results in the economies of indexing countries. Over the last ten years, this index has been established in practice as a leading innovation reference. A more fundamental analysis of the human factor, which is behind innovation, is essential for the development of development policies. Recognizing the key role of innovation, as a driver of economic growth and prosperity, and the need for a broad horizontal vision of innovation, the Global Innovation Index includes indicators that go beyond traditional innovation measures, such as the level of research and development (Cornell University, 2017). 
In order to determine the GII, as the type of output required by the state-level leadership for decision-making, there is a range of inputs that need to be processed in this regard:

1. Institutions.

2. Human capital and research.

3. Infrastructure.

4. Market sophistication and

5. Complexity of business.

The main characteristic for computing the GII is that the overall result is a simple average of the input and output subindices. Also, the Global Innovation Index collects data from more than 30 sources, covering a large spectrum of drivers of innovation and results. The standard framework of the resource is reviewed every year, in transparent workshops, to improve the way innovation is measured.

The primary goal of this research is to develop a tool that can serve as a parametar for underdeveloped countries and countries in transition when directing and implementing state policy, by presenting the correlation coefficients between the SSI, EPI and GII in the countries of the region that are in the transition process. That refers to improving the sustainability of the society and the ecological effects efficiency, where the development of innovations, the overall well-being and the balance of modern systems imposes itself as the ultimate goals.

\section{Review of literature}

Inclusive green economy or 'green growth' primarily refers to environmentally susatainable economic production and consumption that also embrace equity in distribution of resources. Green growth is defined as - 'improved human wellbeing and social equity, while significantly reducing environmental risks and ecological scarcities' (Kumar, 2017).

According to Zugic (2014), countries in the transition process are continually addressing two basic economic issues: macroeconomic stability and structural transformation of the market environment. Macroeconomic stabilization should contribute to the establishment of a distorted economic balance, and solving the problem of structural transformation should enable these countries to efficiently and rationally engage. This requires the formulation of a macroeconomic policy with more efficient measures, mechanisms and instruments for the realization of the chosen objectives and tasks.

The more the economy of a country is integrated into the globalized world economy, the more it has to compete with other countries by simultaneously transforming its economic structure towards a green economy. This competition pressure has the advantage that industry does not look towards the domestic market for customers for its new products but also tries to find new customers for its new green products on the world market. The country is not just reliant on the shielded home market and can initiate a co-evolution process of technological, organizational and institutional changes (Schlor, 2017).

Climate change is a global concern. Growth in energy-related $\mathrm{CO}_{2}$ emissions has been identified as the main cause of climate change. The growing trend will persist if no sustantial efforts on constraining emissions are made (Wang et al., 2018).

Based on Vaninsky's research (2018), data combined on energy consumption from nuclear, hydroelectric, and other renewable sources, are refered to as clean energy since 
$\mathrm{CO}_{2}$ emissions are zero, or very small as compared to fossil fuels. As follows from the data, there are three main GDP producers in the world: OECD (The Organization for Economic Co-operation and Development is a forum of 35 democracies comprising ecnomomies - website http://www.oecd.org provides details) Europe, China and USA, with their GDP shares equal to $18.88 \%, 16.43 \%$ and $15.94 \%$, respectively. They are also the greatest polluters, contributing $12.08 \%, 27.08 \%$ and $16.42 \%$ of the world's $\mathrm{CO}_{2}$ emissions, respectively. It should be mentioned that while Chinese and US economies' $\mathrm{CO}_{2}$ emissions exceed their GDP shares, the emissions are much less in the OECD Europe's economies. The energy from clean sources is mostly consumed in OECD Europe (34.74\%) and the US (30.61\%), comprising $65.35 \%$ of the total.

At the very begining of their research, Djekic et al. (2018) state that in line with the increased global attention of environmental and sustainable impact of the food chain, transportation environmental impacts became polemic tools in various environmental and food policies, and from an enviromental point of view, some authors assume that transportation of trade goods enhances over $20 \%$ of total global $\mathrm{CO}_{2}$ emissions.

Barnhart's et al. (2016) approach offers several advantages for informing conservation targeting decisions. Constructed from multi-input/multi-output productions models, the EPI can accommodate multiple agricultural outputs and types of pollution. The distance functions used to construct the EPI allow for empirical estimation of the production technology without imposing a functional form on the relationship between inputs, outputs and environmental effects. This is particulary useful for identifying and ranking low-performing sites for targeting decisions.

Frank et al. (2016) propose a new methodological framework which allows companies to preform their own benchmark analysis to understand how they are positioned regarding environmental performance in comparison with their competitors. They suggested framework that can help to improve environmental competitiveness within the industry and thereby contribute to environmental sustainbility of the sector.

Also, Zuo et al. (2017) use the environmental performance index to indicate the environmental scores of China's 30 provincial administrative regions, which were developed from the pilot Environmental Performance Index that was published in 2002. Their studies provide useful environmental sugestions for local government.

Sustainable development measuring initiatives have reached such volume that perhaps a sustainable development index revolution is now warranted. As with all rapidly growing academic and professional topics, theoretical and applied research can become so focused on improving accuracy of current practices that they often lose sight of practical application. In this regard, measuring progress toward sustainbility now resembles true cost accounting rather than rapidly employable tools useful for the developed and developing world alike (Shaker, 2018).

The SSI covers sustainability in its broadest sense, including social, environmental, ecological and institutional aspects, while most other indexes do so only partly. One of the main objections to the SSI is the aggregation of all indicators into one single figure for the index. Should one only consider this figure in isolation, the results may be misleading and can easily be misused (Van de Kerk et al., 2008).

Many rapidly growing economies reveal similar findings, with some exceptions. According to the Dual Citizen LLC (2016), India, Bangladesh and Senegal had GDP growth between 6-8\% in 2016. On the other hand, these countries perform poorly on the new global green economy index, raising the question of what kind of growth these nations are realizing and how sustainable it is. Interestingly, Cambodia realized the 
highest improvement on the global green economy index in 2016 compared to 2014. Given that Cambodia is projected to grow at $7 \%$ in 2016, it represents a possible model for how green growth can be integrated in similar developing countries. These overall findings are just the beginning of the snapshot that provides on the state of the global green economy today and the progress countries are making within it.

Dasic (2014) in his research states that the energy security is essential for sustainable economic development and the stability of the country. The inability to access energy resources causes serious economic disturbances and political instability. In the conditions of the global economy, disruptions are easily transmitted and it is, therefore, essential to permanently provide energy resources and make an effort to reduce the socalled energy poverty most affecting countries in transition (the countries of Southeastern Europe) and third world countries. The problem can be solved by the introduction of alternative or renewable energy sources. This greatly alleviates the problem, with the positive effects of helping local economic development and reducing the greenhouse gas emissions. However, for a successful solution, there is a need for awareness of the existence of problems, political will and the ability to implement the solution. South-East European countries are characterized by a good geostrategic position, which should be used in the field of energy in order to achieve the strategic goals of regional development.

By looking at the previous research, the results of the correlation between the index of sustainability, green economy, innovations, etc. were tested, both in the economies in the transition process, and in the developed economies, which significantly helped this research process, on the question of knowledge, on the one hand, and on the other hand, the systematization of the information provided.

For instance, the results of Van de Kerk et al. (2008) research show that one of the main objections to the SSI is the aggregation of all indicators into one single figure for the index. Should one only consider this figure in isolation, the results may be misleading and can easily be misused. This objection is inextricably bound up with aggregation into one final figure. It stresses the importance of presenting all the results of the SSI - values of all indicators and categories - in a transparent and easily understandable way. Since the ultimate goal is to achieve a score of 10 - expressing full sustainability for each indicator - there can be no trade-off between the indicators or categories.

A study of 30 Western Hemisphere nations was presented in Shaker (2018) research shows that, its overall goal was to create the first mega-index of sustainable development (MISD), with the aim to improve humanity's ability to calculate progress toward sustainability through an inductive approach. In doing so, 31 known indices were reduced into seven underlying dimensions of sustainable development, then normalized 0-100, and aggregated by their geometric mean. The seven orthogonal axes (latent dimensions) were subjectively articulated as: (1) socioeconomic well-being synergies; (2) economic freedom and democracy; (3) environmentally efficient happiness; (4) ecosystem well-being; (5) peace to economic vulnerability tradeoff; (6) natural resources protection; and (7) environmental stewardship and risk resilience. Overall, this study found that the underlying socioeconomic themes of sustainability dwarfed environmental themes, signifying a greater need for more simple, accurate, and scaleless (spatial and temporal) biogeophysical indicators. Using Pearson's correlation and bivariate ordinary least squares (OLS) regression, 11 common development indicators were then explored regarding collinearity and explanatory power of the 
sustainable development dimensions and MISD. In sum, winning countries were characterized by low population density, increased forestland, decreased urban, and larger country area. The presented evidence is sufficient to suggest that just a few common and freely available indicators could eventually capture all present dimensions of sustainable development.

The aim of Latif et al. (2017) research as to develop an interactive model to develop the sustainability index for small and medium scale manufacturing industry.

In addition, Almeida et al. (2016) claim that Composite Index of Environmental Performance and Environtmental Performance Index models have initial objectives that guide all following steps, and there are many available variables that can be used to construct an ecological composite index. Some methodological techniques are used in each phase and the choices of the best methods were made based on theoretical background. Based on the three cited factors, the Composite Index of Environmental Performance and Environtmental Performance Index models are decomposed and analyzed in order to determine possible differences and similarities. The Composite Index of Environmental Performance and Environtmental Performance Index indicators have similar essential goals, which are to measure and rank environmental performance by country, although the focuses are different due the methods used to aggregate single variables. The first tool focuses on five dimensions, and the second focuses on nine environmental policy categories and two objectives ecological issues. In other words, the information provided by one, can be expanded by the other index. On the other hand, it is only possible to compare both indexes at the final stage when they are finished, and it is not possible to compare within subcategories. For example: it is impossible observe pressure on the ecosystem using the EPI, and it is impossible to assess ecosystem vitality using the CIEP, because they are aggregated through different categories. Both composite indexes analyzed use a positive approach because they measure performance, and thus the higher the value, the better are the results.

Also, Zuo et al. (2017) use EPI to evaluate China's environmental performance at the provincial level and then identifies weaknesses inenvironmental management for the purpose of improving government efficiency and solving severe environmental problems.

Crespo et al. (2016) explain the use of GII in their research. Their study should stimulate new research projects that compare the performance of innovation systems that distinguish between different levels of economic development. For instance, an extension might keep the sample together or might split the country sample into more disaggregated groups in order to understand the alternative recipes that could lead countries to high innovation performance. Another possible development deals with asymmetric causality. This approach might lead to better understanding of the causal conditions that lead countries to low innovation performance.

\section{Materials and methods}

The methodology of this article is based on the implementation of the sustainability index, which consists of the SSI and the EPI, and their connection with the GII, or the establishment of mutual correlation.

The subject of correlation analysis is to examine the mutual strength of the relationship and the dependence between sustainability and innovation. The selected variables are the SSI, the EPI and the GII. The examination of the direction and strength 
of the interaction of these three indexes is carried out on the basis of correlation analysis. It is also implemented on a sample of ten countries: Albania, Bosnia \& Herzegovina (B\&H), Bulgaria, Croatia, Hungary, Macedonia, Montenegro, Romania, Serbia and Slovenia (see Figure 1).

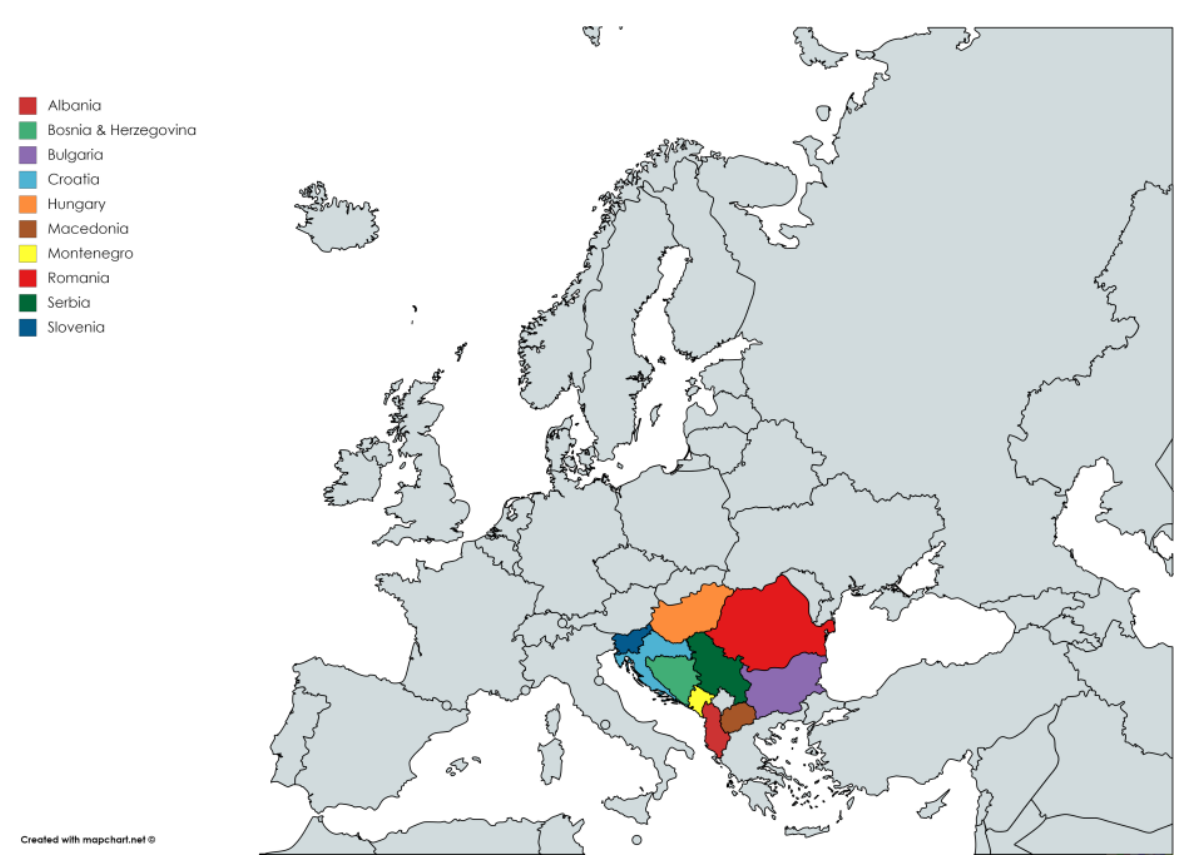

Figure 1. The location of the countries involved in the presented study

Classification (systematization) is the process of organizing information into categories or classes so that data can be more clearly analyzed or understood. Therefore, this research carried out the classification of the countries of Central and Eastern Europe, which are the subject of research, according to the following (Table 1).

Table 1. Country classification according to two different criteria

\begin{tabular}{c|c|c}
\hline \multirow{2}{*}{ Country } & \multicolumn{2}{|c}{ Criterion } \\
\cline { 2 - 3 } & EU Membership Status & Economy Development Status \\
\hline Albania & Candidate & Economy in transition \\
Bosnia \& Herzegovina & Potential candidate & Economy in transition \\
Bulgaria & Member & Developed economy \\
Croatia & Member & Developed economy \\
Hungary & Member & Developed economy \\
Macedonia & Candidate & Economy in transition \\
Montenegro & Candidate & Economy in transition \\
Romania & Member & Developed economy \\
Serbia & Candidate & Economy in transition \\
Slovenia & Member & Developed economy \\
\hline
\end{tabular}

${ }^{a}$ Information Source: Development Policy and Analysis Division of the Department of Economics and Social Affairs of the United Nations Secreteriat

Thus, the classification of countries in this survey will be based on the status of membership in the European Union, on the one hand, or on the basis of economic development, on the other. 
The time interval to be tested is from 2010 to 2016. Testing the direction and strength of the interconnection will be expressed by the coefficient, using the Pearson linear method. It is a covariance of standardized variables X and Y. It is calculated using the following formula:

$$
r=\frac{\sum_{i=1}^{n} x_{i} y_{i}-n \bar{x} \bar{y}}{n \sigma_{x} \sigma_{y}}
$$

Or alternatively:

$$
r=\frac{\sum_{i=1}^{n} x_{i} y_{i}-n \bar{x} \bar{y}}{\sqrt{\left(\sum_{i=1}^{n} x_{i}{ }^{2}-n \bar{x}^{2}\right)\left(\sum_{i=1}^{n} y_{i}{ }^{2}-n \bar{y}^{2}\right)}}
$$

where:

- $n$ is the sample size.

- $X_{i}, Y_{i}$ are the sample points indexed with $i$.

- $\sigma_{x}$ is standard deviation of $X$.

- $\sigma_{y}$ is standard deviation of $Y$.

and the sample mean calculation would be

$$
\bar{x}=\frac{1}{n} \sum_{i=1}^{n} x_{i} \quad \bar{y}=\frac{1}{n} \sum_{i=1}^{n} y_{i}
$$

The coefficient takes values from a closed interval between -1 and 1 . The zero value indicates that there is no linear correlation; the value plus one denotes a perfect positive fit, and minus one shows a perfect negative fit. The value of the coefficient is closer to 1 , the linear bond is stronger. The lower value of the coefficient does not necessarily indicate a weak link between the variables, since there may be a very strong correlation between the variables, but the curvilinear, so the application of the linear coefficient of correlation is not appropriate in this case (Buturac and Ignjatijević, 2017).

Data from the Global Innovation Index Report (2010-2016), the Environmental Performance Index Report (2010-2016) and the results of the Sustainable Society Foundation research (2010-2016), are taken as information source, based on which this research was conducted.

\section{Sustainable Society Index (SSI)}

In the SSI, the parameters of human well-being and environmental performance are integrated. These are the goals that each country should strive for, since economic wellbeing, without the previous two, can not be sustainable.

For the SSI only public data sources that are current and available are used. However, data reliability still leaves room for arbitrariness. Especially in the production 
of time series, processors are faced with many irregularities and obstacles in the creation of data. This problem can be reduced over time, as the significance of statistical data is now generally recognized.

Aggregation is an abstraction in which the connection between two objects or more object types is treated as an object at a higher level of abstraction. Because at the same time it is an object and a connection, aggregation is often referred to as a mixed type of object-connections. Aggregation objects are called aggregation components. For the aggregation of parameters of the SSI, a geometric average is used. The arithmetic average offers the possibility of compensation, where the low value of one indicator can be compensated by the high value of the other indicator. Since sustainability does not allow for compensation, it is best to use geometric compensation.

Van de Kerk et al. (2008) in their research demonstrated that the SSI is a simple instrument for assessing a country's sustainbility. The SSI, based on a solid definition, shows at a glance the present level of sustainability of a country and the distance to full sustainability. The SSI offers a country a practical tool for defining targets on its way to sustainability and for monitoring the progress over time.

\section{The SSI calculation methodology}

For lack of a scientific basis for the attribution of different weights to the indicators, every indicator has recieved the same weight for the aggregation into dimensions. In the data tables it is presented the averages per country. Thus one can notice the impact of weighting per person or per country. For each indicator the formula is shown, in which $\mathrm{F}(\mathrm{x})$ is the indicator score and $\mathrm{X}$ the value of the raw data (Table 2). In addition the range of validity is indicated.

Because of all of the above, the values of the three parameters are not aggregated into the total index, so that the researcher, could decide either for individual data, or for a summary result. Taking previously into consideration, the Sustainable Society Index data are trusted data, not the calculation of the authors, except the fact that we decided on the aggregate score of the index, which is presented in Table 3.

In the period from 2010 to 2016, the highest progress, according to the results of the conducted measurements (see Table 3), was achieved by Romania with a coefficient of 1.5, while the smallest progress was achieved by Albania with a coefficient of 0 . The negative trend was achieved by the two countries, Montenegro and Slovenia (-0.4 and 0.2 ), however, this data should be taken with reserve, given that, according to the latest measurements from 2016, Slovenia is the second country in the region (coefficient of the Sustainable Society Index: 6.2), immediately behind the leading Romania (6.8).

\section{Environmental Performance Index (EPI)}

According to Almeida and Garcia-Sanchez (2016), EPI is one of the most known indexes, and it is used in several studies and frequently receives innovations and improvements. The EPI has published an annual report that ranks 180 countries, according to ecological performance comprised of twenty two four variables, combined into ten policy issue that are aggregated in two different groups (health of the environment and vitality of ecosystems).

These measures enable the quantitative expression of the effectiveness of the implementation of environmental performance policies at the national level. These results highlight advanced countries and those lagging behind in this segment, giving insights into best practices, and providing guidance for countries that are striving to be 
leaders in environmental sustainability. The innovations in EPI data from 2018 and the methodology generated a new ranking based on modern approaches in natural science and analysis.

According to research of Yale University presented in EPI Report (2018), this index draws attention to the issues on which policy makers need to take further initiative. Although the EPI provides an analytical framework suitable for a more rigorous creation of an environmental policy, it also reveals and points to more serious failures through data. According to the Foundation for Environmental Protection, EPI projects that data collection, reporting and verification is necessary, through a series of ecological problems. Existing deficiencies are particularly evident in the areas of sustainable agriculture, water resources and waste management. Therefore, data systems are exceptional support for better management of sustainable development challenges.

Table 2. Calculation formulas of the SSI

\begin{tabular}{|c|c|c|}
\hline Indicator number & Indicator Name & Formula \\
\hline 1 & Sufficient food & $\begin{array}{c}\mathrm{F}(\mathrm{X})=(100-X) / 10 \text { if } 5 \leq \mathrm{X} \leq 100 \\
\mathrm{~F}(\mathrm{X})=10 \text { if } \mathrm{X}<5\end{array}$ \\
\hline 2 & Sufficient to drink & $\begin{array}{c}\mathrm{F}(\mathrm{X})=\mathrm{X} / 10 \\
0 \leq \mathrm{X} \leq 100\end{array}$ \\
\hline 3 & Safe Sanitation & $\begin{array}{c}F(X)=X / 10 \\
0 \leq X \leq 100\end{array}$ \\
\hline 4 & Education & $\begin{array}{c}F(X)=X / 10 \text { if } 0 \leq X \leq 100 \\
F(X)=10 \text { if } X>100\end{array}$ \\
\hline 5 & Healthy Life & $\begin{array}{c}\mathrm{F}(\mathrm{X})=((\mathrm{X}-20) / 60) * 10 \\
20 \leq \mathrm{X} \leq 80\end{array}$ \\
\hline 6 & Gender Equality & $\begin{array}{c}\mathrm{F}(\mathrm{X})=\mathrm{X} * 10 \\
0 \leq \mathrm{X} \leq 1\end{array}$ \\
\hline 7 & $\begin{array}{c}\text { Income } \\
\text { Distribution }\end{array}$ & $\begin{array}{c}\mathrm{F}(\mathrm{X})=\mathrm{EXP}(-0,1 *(\mathrm{X}-4,5)) * 10 \\
\text { If } 4,5 \leq \mathrm{X} \leq 168, \mathrm{~F}(\mathrm{X})=0 \text { if } \mathrm{X}>168\end{array}$ \\
\hline 8 & Population Growth & $\begin{array}{c}F(X)=-0,0067 * X^{2}-0,4333 * X+8 \text { if }-5<X<15 \\
F(X)=0 \text { if } X \geq 15, F(X)=10 \text { if } X<-5\end{array}$ \\
\hline 9 & Good Governance & $\begin{array}{c}\mathrm{F}(\mathrm{X})=((\mathrm{X}+15) / 30) * 10 \\
-15 \leq \mathrm{X} \leq 15\end{array}$ \\
\hline 10 & Biodiversity & $\mathrm{F}(\mathrm{X})=(\mathrm{F}(\mathrm{X} 1)+\mathrm{F}(\mathrm{X} 2)) / 2$ \\
\hline 11 & $\begin{array}{l}\text { Renewable Water } \\
\text { Resources }\end{array}$ & $\begin{array}{c}\mathrm{F}(\mathrm{X})=(100-\mathrm{X}) / 10 \text { if } 0 \leq \mathrm{X} \leq 90 \\
\mathrm{~F}(\mathrm{X})=0 \text { if } \mathrm{X}>90\end{array}$ \\
\hline 12 & Consumption & $\begin{array}{c}\mathrm{F}(\mathrm{X})=10-3 * \mathrm{X} * 2 / 1,8 \text { if } 0 \leq \mathrm{X} \leq 2,7 \\
\mathrm{~F}(\mathrm{X})=0 \text { if } \mathrm{X}>2,7\end{array}$ \\
\hline 13 & Energy Use & $\begin{array}{c}\mathrm{F}(\mathrm{X})=-2 * \mathrm{X}+10 \text { if } \mathrm{X} \leq 5 \\
\mathrm{~F}(\mathrm{X})=0 \text { if } \mathrm{X}>5\end{array}$ \\
\hline 14 & Energy Savings & $\begin{array}{c}F(X)=25 * X+5 \text { if }-0,2 \leq X \leq 0,2 \\
F(X)=0 \text { if } X<-0,2, F(X)=10 \text { if } X>0,2\end{array}$ \\
\hline 15 & Greenhouse Gases & $\begin{array}{c}F(X)=10-X \text { if } 0 \leq X \leq 10 \\
F(X)=0 \text { if } X>10\end{array}$ \\
\hline 16 & Renewable Energy & $\begin{array}{c}F(X)=X / 10 \text { if } 0 \leq X \leq 100 \\
F(X)=10 \text { if } X>100\end{array}$ \\
\hline 17 & Oganic Farming & $\mathrm{F}(\mathrm{X})=9 *(1-\mathrm{EXP}(-0,25 * \mathrm{X}))+1$ \\
\hline 18 & Genuine Savings & $\mathrm{F}(\mathrm{X})=10 * \operatorname{ARCTAN}(0,2 * \mathrm{X}) / \pi+5$ \\
\hline 19 & $\begin{array}{l}\text { Gross Domestic } \\
\text { Product }\end{array}$ & $\begin{array}{c}\mathrm{F}(\mathrm{X})=10 *(1,01-\mathrm{EXP}(-0,000065 * \mathrm{X})) \text { if } 0 \leq \mathrm{X} \leq 70000 \\
\mathrm{~F}(\mathrm{X})=10 \text { if } \mathrm{X}>70000\end{array}$ \\
\hline 20 & Employment & $\begin{array}{c}\mathrm{F}(\mathrm{X})=\mathrm{EXP}(-0,1 * \mathrm{X}) * 10 \text { if } 0 \leq \mathrm{X} \leq 60 \\
\mathrm{~F}(\mathrm{X})=1 \text { if } \mathrm{X}>60\end{array}$ \\
\hline 21 & Public Debt & $\begin{array}{c}\mathrm{F}(\mathrm{X})=-3,8 * \operatorname{ARCTAN}(0,06 * \mathrm{X}-3,5)+5 \text { if } 2,5 \leq \mathrm{X} \leq 117 \\
\mathrm{~F}(\mathrm{X})=0 \text { if } \mathrm{X} \geq 117, \mathrm{~F}(\mathrm{X})=10 \text { if } \mathrm{X}<2,5\end{array}$ \\
\hline
\end{tabular}


Table 3. Sustainable Society Index of the selected countries in transition

\begin{tabular}{c|c|c|c|c||c|c|c|c|c}
\hline Country / Yr & $\mathbf{2 0 1 0}$ & $\mathbf{2 0 1 2}$ & $\mathbf{2 0 1 4}$ & $\mathbf{2 0 1 6}$ & Country / Yr & $\mathbf{2 0 1 0}$ & $\mathbf{2 0 1 2}$ & $\mathbf{2 0 1 4}$ & $\mathbf{2 0 1 6}$ \\
\hline \hline Albania & 5.90 & 5.90 & 5.80 & 5.40 & Macedonia & 4.90 & 5.70 & 5.40 & 5.40 \\
B\&H & 4.50 & 4.60 & 4.70 & 4.80 & Montenegro & 5.60 & 6.00 & 6.10 & 6.00 \\
Bulgaria & 5.70 & 6.00 & 5.90 & 6.10 & Romania & 6.10 & 6.40 & 6.50 & 6.80 \\
Croatia & 6.00 & 6.20 & 5.80 & 5.90 & Serbia & 5.40 & 5.30 & 5.20 & 5.30 \\
Hungary & 5.80 & 5.90 & 6.00 & 6.20 & Slovenia & 6.60 & 6.60 & 6.10 & 6.30 \\
\hline
\end{tabular}

Source: http://www.ssfindex.com/data-all-countries/

\section{The EPI calculation methodology}

To create the EPI, raw datasets is transformed into comparable performance indicators, which requires standardizing raw values according to population, land area, gross domestic product, and other common units of measurement. Then statistical transformations are performed to normalize data distributions and ensure weights assigned in the aggregation phase affect data as intended.

The transformed data are used to calculate performance indicators. EPI indicators are developed using a 'proximity-to-target' methodology, which assesses how close each country is to an identified policy target. The targets are high performance benchmarks defined primarily by international or nation policy goals or established scientific thresholds.

A high performance benchmark can be determined through an analysis of the bestperforming countries. Scores are then converted to a scale of 0 to 100 by simple arithmetic calculation, with 0 being the farthest from the target and 100 being the closest. In this way, scores convey analogous meaning across indicators, policy issues, and throught the EPI.

Each indicator is weighted within the issue categories to create a single issue category score. These weightings are generally set according to the quality of the underlying data, as well as an indicator's relevance or fit for assessing a given policy issue. If the underlying data for a particular indicator is less reliable or relevant than others in the same issue category, the indicator will be weighted less. Policy issues are weighted approximately equally within their objective. Contigent on the data strength in each category, slight adjustments to this weighting can be made (Yale University, 2018).

Countries only receive scores for issues that are 'material' or relevant to their environmental performance. The exclusion of certain issues for some countries proportionally increases the weight on other indicators within a policy issue and objective. The two objectives, Environmental Health and Ecosystem Vitality, are weighted equally to achieve a single value, the EPI score, for each country.

$$
E P I=\sum_{i=1}^{n}(W i X i)
$$

where

- $i$ is total number of the indicator.

- $n$ is total number of all indicators.

- $W i$ is weight of the $i_{\text {th }}$ indicator.

- $X i$ is standard value of the $i_{\text {th }}$ indicator (Zuo et al., 2017). 
It is interesting to compare the EPI trend in the countries of the region, taken as a sample in this survey. If we take into consideration the indicators from 2016, it can be established that most of the countries in the region are in front of Serbia, when index indices are considered (see Table 4). The three countries have an unfavorable outcome compared to the Republic of Serbia, which are Albania, B\&H and Macedonia.

Table 4. Environmental Performance Index of the selected countries in transition

\begin{tabular}{c|c|c|c|c||c|c|c|c|c}
\hline Country / Yr & $\mathbf{2 0 1 0}$ & $\mathbf{2 0 1 2}^{\mathbf{a}}$ & $\mathbf{2 0 1 4}$ & $\mathbf{2 0 1 6}$ & Country / Yr & $\mathbf{2 0 1 0}^{\mathbf{2 0 1 2}}$ & $\mathbf{2 0 1 4}$ & $\mathbf{2 0 1 6}$ \\
\hline \hline Albania & 71.14 & 65.85 & 54.73 & 74.38 & Macedonia & 60.60 & 46.96 & 50.41 & 78.02 \\
B\&H & 55.90 & 36.76 & 45.79 & 63.28 & Montenegro $^{\mathrm{c}}$ & $/$ & $/$ & 78.89 & 78.89 \\
Bulgaria & 62.50 & 56.28 & 64.01 & 83.40 & Romania & 67.00 & 48.34 & 83.24 & 83.24 \\
Croatia & 68.70 & 64.16 & 62.23 & 86.98 & Serbia & 69.40 & 46.14 & 78.67 & 78.67 \\
Hungary & 69.10 & 57.12 & 70.28 & 84.60 & Slovenia & 65.00 & 62.25 & 76.43 & 88.98 \\
\hline
\end{tabular}

Source: Environmental Performance Index Report (2010-2016). Publisher: Yale University: Center for Environmental Law \& Policy

${ }^{a}$ Scores and rankings for the 2012 EPI cannot be compared with scores and rankings from eralier releases of the EPI owing to changes in data and methodology

${ }^{\mathrm{b}}$ Ibid.

${ }^{c}$ No data available for Montenegro in the specified years

As it is presented in Table 4, between the countries of the region, which are highly ranked on the world ranking list, the difference in the index coefficient is negligible (88.98 - 83.24). According to these results, Slovenia is ahead, followed by Croatia, Hungary, Bulgaria and Romania.

A more sensitive difference in the value of the measured index was recorded in Montenegro (78.89), Serbia (78.67) and Macedonia (78.02). The following countries are followed by Albania (74.38) and B\&H (63.28).

Data source for the EPI come from international organizations, research institutions, academia, and government agencies. These sources use a variety of techniques, including (Yale University, 2018):

- Remote sensing data collected and analyzed by research partners.

- Observations from monitoring stations.

- Surveys and questionnaires.

- Academic research.

- Estimates derived from both on-the-ground measurements and statistical models.

- Industry reports; and

- Government statistics, reported either individually or through international organizations, that may or may not be independently verified.

Taking this into consideration, the Environmental Performance Index data are trusted data, not the calculation of the authors.

\section{The Global Innovation Index (GII)}

The Global Innovation Index is important for achieving economic progress and competitiveness in the market, both in developed countries and in countries in transition. Many countries, when implementing their economic policies, include this index in the center of state strategies.

Also, one of the reasons for introducing this kind of measurement of the achieved results in terms of innovation in the economy of a particular country is to provide timely 
and accurate data to the state leadership, which is an important prerequisite for decisionmaking and improvement of innovation policies. This does not mean that the GII is merely the ranking of the economies of countries that are subject to indexing, based on certain parameters, but also in this way to assess the conditions that incite the potent trend of innovation, that is, to assess the outcome of the introduction of concrete improvements (Cornell University, 2017).

Although the final results are presented in several forms, in order to provide a better comparison of indicators, the GII is more focused on understanding and analyzing innovations, that is, identifying targeted policies, good practices and instruments that help improve innovation. Previously, comprehensive indexing is used at the level of the index, subindex or at the level of individual data used to monitor the performance over a specific time period, as well as to develop in relation to countries in the region.

According to the Cornell University's Global Innovation Index Report (2017) an innovation is the implementation of a new or significantly improved product (good or service), a new process, a new marketing method, or a new organizational method in business practices, workplace organization or external relations. The Global Innovation Index is not meant to be the ultimate and definitive ranking of economies with respect to innovation. Measuring innovation outputs and impacts remains difficult, hence great emphasis is placed on measuring the climate and infrastructure for innovation and on assessing related outcomes. Today innovation capability is seen more as the ability to exploit new technological combinations; it embraces the notion of incremental innovation and 'innovation without research.

\section{The GII calculation methodology}

The Global Innovation Index is an evolving project that builds on its previous editions while incorporating newly available data and that is inspired by the lateset research on the measurement of innovation. The GII relies on two sub-indicies - the Innovation Input Sub-Index, and the Innovation Output Sub-Index - each built around key pillars (Figure 2).

Five input pillars capture elements of the national economy that enable innovative activities: (1) Institutions, (2) Human capital and research, (3) Infrastructure, (4) Market sophistication and (5) Business sophistication. Two output pillars capture actual evidence of innovation outputs: (6) Knowledge and technology outputs and (7) Creative outputs (Cornell University, 2017).

Each pillar is divided into sub-pillars and each sub-pillar is composed of individual indicators ( 80 in total). Sub-pillar scores are calculated as the weighted average of individual indicators; pillar scores are calculated as the weighted average of sub-pillar scores. Four measures are then calculated:

- Innovation Input Sub-Index: is the simple average of the first five pillar scores.

- Innovation Output Sub-Index: is the simple average of the last two pillar scores.

- The overall GII score is the simple average of the Input and Output Sub-Indicies.

- The innovation Efficiency Ratio is the ratio of the Output Sub-Index over the Input Sub-Index.

Taking previously into consideration, the Global Innovation Index data are trusted data, not the calculation of the authors.

Expectedly, the values presented in the Table 5 show that innovation in the EU Member States is more prevalent. The largest coefficient in 2016, from the countries that are the subject of consideration, has Slovenia (45.97) as a strong innovator, while 
the lowest coefficient is Albania (28.38). The countries who scored coefficient values among this range $(28.38$ - 45.97) also have their innovation status - moderate and modest innovators. It is interesting that in the period from 2010 to 2016, the GII registered a negative trend (Hungary, Serbia, Montenegro, B\&H, and Albania), while in the period after this year, there was an increase. The status of innovators, in fact, follows the status of development and membership status in the European Union, which are previously set criteria for the classification of countries that are the subject of this research.

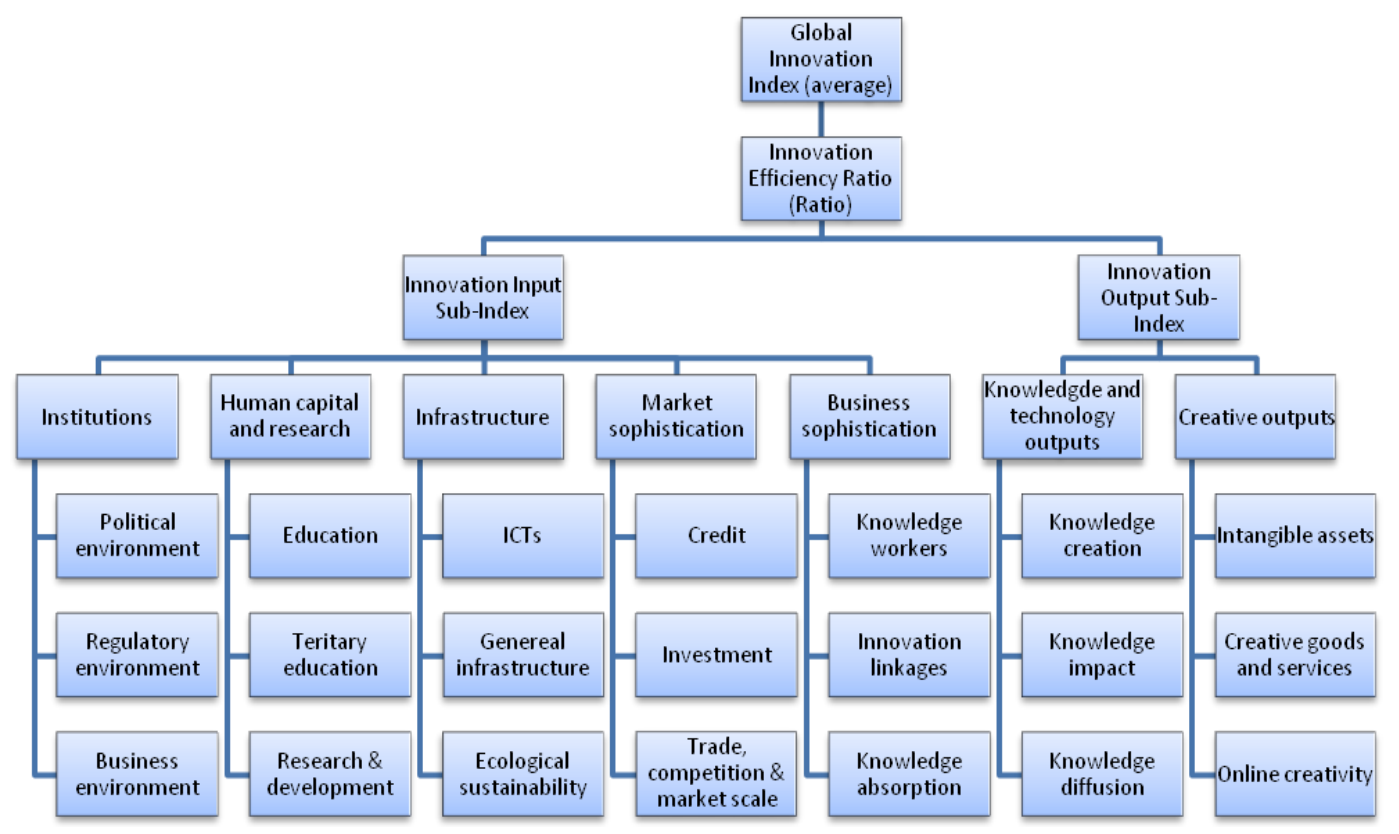

Figure 2. The Global Innovation Index Framework

Table 5. Global Innovation Index of the selected countries in transition

\begin{tabular}{c|c|c|c|c||c|c|c|c|c}
\hline Country / Yr & $\mathbf{2 0 1 0}^{\mathbf{a}}$ & $\mathbf{2 0 1 2}$ & $\mathbf{2 0 1 4}$ & $\mathbf{2 0 1 6}$ & Country / Yr & $\mathbf{2 0 1 0}^{\mathbf{b}}$ & $\mathbf{2 0 1 2}$ & $\mathbf{2 0 1 4}$ & $\mathbf{2 0 1 6}$ \\
\hline \hline Albania & 2.86 & 30.40 & 30.47 & 28.38 & Macedonia & 2.89 & 36.20 & 36.90 & 35.40 \\
B\&H & 2.58 & 34.20 & 32.43 & 29.62 & Montenegro & 3.08 & 40.10 & 37.01 & 37.36 \\
Bulgaria & 3.26 & 40.70 & 40.74 & 41.42 & Romania & 3.22 & 37.80 & 38.08 & 37.90 \\
Croatia & 3.28 & 40.70 & 40.75 & 38.29 & Serbia & 2.68 & 40.00 & 35.89 & 33.75 \\
Hungary & 3.54 & 46.50 & 44.61 & 44.71 & Slovenia & 3.80 & 49.90 & 47.23 & 45.97 \\
\hline
\end{tabular}

Source: https://www.globalinnovationindex.org/home

${ }^{a}$ Scores and rankings for the 2010 GII cannot be compared with scores and rankings from later releases of the GII owing to changes in data and methodology

${ }^{\mathrm{b}}$ Ibid.

\section{Results}

Based on previously explained indicators of sustainable society, environmental performance and global innovations, in the first part of the research, the center was moved to determine and describe the coefficient of mutual correlation between the SSI and the GII. 
Since this is parametric statistics, where the coefficient of variation is less than 30 (in the concrete case SSI $=10.1100775091025$, GII $=15.5680187865172$ ), the Pearson method of correlation was applied, thus calculating the correlation coefficient of these two indices.

The correlation coefficient of the SSI and the GII is 0.749413095249505 , that is, 0.75 , which means that the correlation of these two parameters is above all: positive (> $0.50)$ and then strong.

In Figure 3, the correlation of these two indices is shown, along with the variation coefficients, also mentioned. Based on this, we conclude that a low SSI value (living standard of the population, environmental protection and economic well-being) also contributes to a low GII value. Thus, the underdevelopment of innovation is a result of low living standards and underdeveloped economies. This group of countries includes Albania and $\mathrm{B} \& \mathrm{H}$.

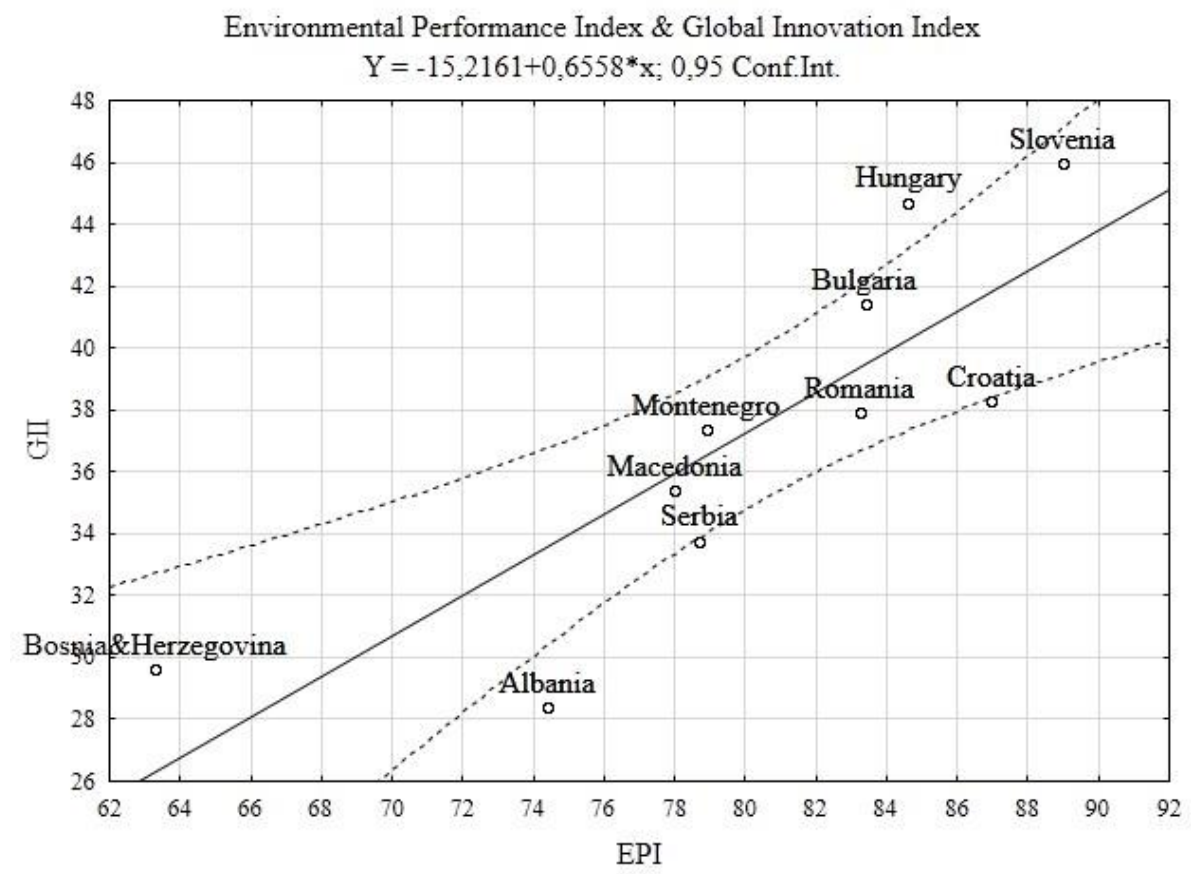

Figure 3. Correlation between EPI \& GII of the selected countries in transition

The group of non-EU countries is led by Montenegro, followed by Macedonia and Serbia. Also, on the basis of an analysis of the mutual correlation of the index, we conclude that the countries of the regions that are members of the EU, have significantly better results than the rest of the considered sample. This group is led by Slovenia and Hungary, followed by Bulgaria, Croatia and Romania. The results of this group confirm that economic prosperity and high living standards of the population directly influence the level of innovation in the domestic economy.

Smilarly, comparing the Environmental Performance Index to the Global Innovation Index, we arrive at the results, and interpretations of the results close to the previous one.

Since in this case the coefficient of variation $<30(\mathrm{EPI}=9.22410037158007, \mathrm{GII}=$ 15.5680187865172), the Pearson method of correlation was used. Correlation 
coefficient of the Environmental Performance Index and Global Innovation Index is 0.834337304281034 . The correlation between these two parameters is positive, and more pronounced, than in the previous case.

The division of countries by groups is identical to the previous interpretation of the results. Furthermore, the low efficiency of environmental protection, that is, the low level of people's awareness of the need for environmental protection, directly affects the low level of innovation in the economies of these countries that are in transition.

In this index clash, the results are even more dramatically determined (see Figure 4). The worst results are recorded by Albania and $\mathrm{B} \& \mathrm{H}$, which still have the status of underdeveloped transition countries. A group of non-EU countries that are on the right path to achieving the goals of the set strategies and policies is led by Montenegro, followed by Macedonia and Serbia. Far ahead are the EU Member States, led by Slovenia and Hungary, followed by Bulgaria, Croatia and Romania.

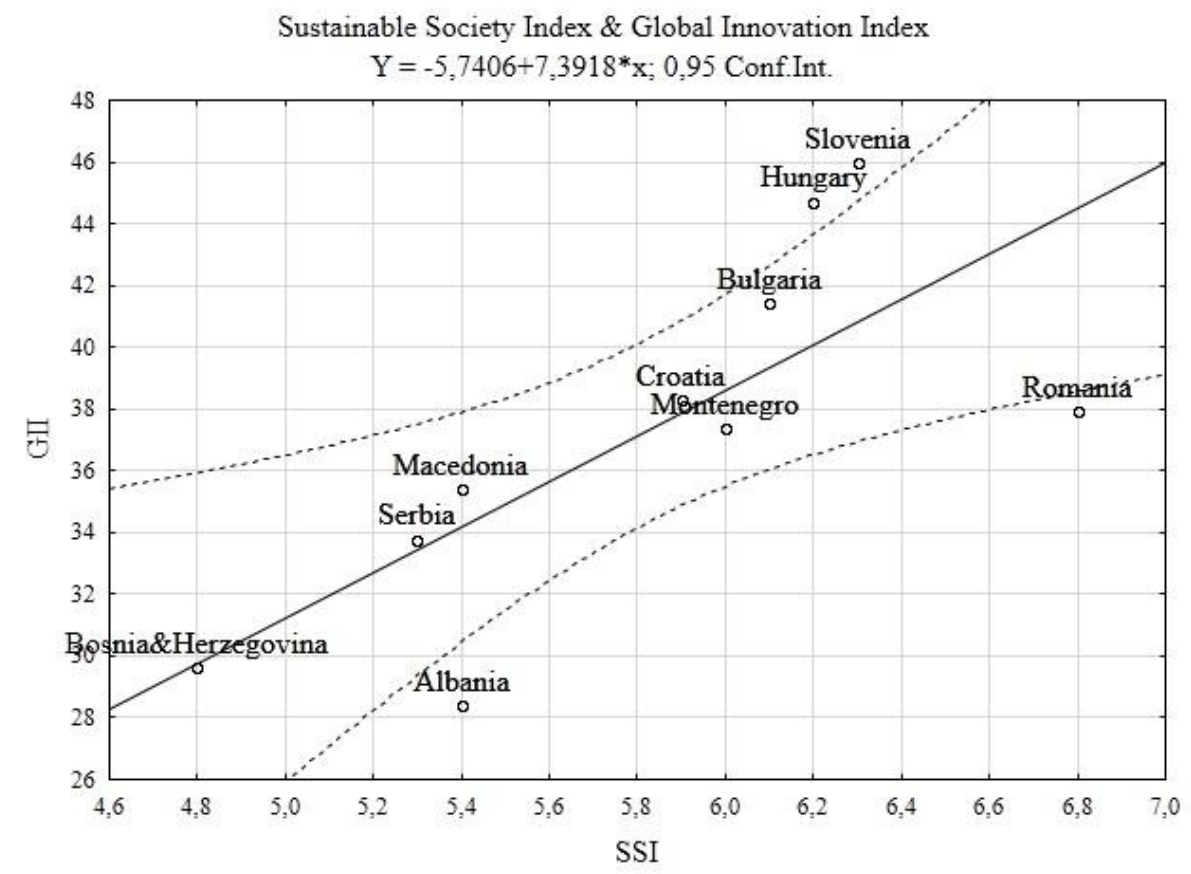

Figure 4. Correlation between SSI \& GII of the selected countries in transition

The example of Slovenia, perhaps, is the best presentation of what each country in transition is tending to. The achieved high, desired results in the field of environmental protection directly influence the higher financial allocations and investments in innovations in the field of economy.

\section{Discussion}

Taking into account all the results obtained, the conclusion is that the paramteres in the subject of the conducted research are interconnected, as evidenced by the high coefficient of correlation. Looking at the individual results of countries in the region, they can be grouped according to the status of countries for EU membership. 
On a sample of ten countries in the region, which are related to a common transition, there is still a certain grouping, which is noticed in the graphic representation of the obtained results. Namely, the first group of countries are the countries that are in the status of a potential candidate for EU membership. This group belongs to B\&H. However, according to unfavorable results in the considered areas of social activity, although in the status of EU candidate country, Albania joins B\&H on the ranking list of the Sustainability and Innovation Index.

The next group of countries is a group of countries that are in the process of joining the EU. This group is led by Montenegro, followed by Serbia and Macedonia (although the country with the candidate status).

Expectedly, at the top of the list of countries in the region, Slovenia is the most developed country with the largest investments in innovation, which is the result of a favorable economic situation in the economy of this country, as well as high awareness of the need for environmental protection. Other EU member states are: Hungary, Bulgaria, Romania and Croatia.

On the other hand, a high degree of correlation of parameters, whose interdependence is researched, indicates interaction, and encouraging positive trends in the growth of innovation and improving the quality of life and living standards of the inhabitants of these countries. In order for the less developed countries in transition to reach the targeted level of sustainability of the society and the efficiency of environmental performance, it is necessary for the state leadership to direct and lead a more efficient policy towards the improvement of these areas. In this way, inevitably, as a consequence of this action, the development of innovations in the economies of these countries will be imposed, which, as the ultimate goal, represents the overall well-being and balance of modern systems.

\section{REFERENCES}

[1] Almeida, T. A. N., Garcia-Sanchez, I-M. (2016): A comparative analysis between composite indexes of environmental performance: An analysis on the CIEP and EPI. Environmental Science \& Policy 64: 59-74.

[2] Barnhart, B., Bostian, M., Whittaker, G., Grosskopf, S., Fare, R. (2016): Prioritizing conservation for the reduction of Gulf hypoxia using an environmental performance index. - Ecological Indicators 66: 235-241.

[3] Buturac, G., Ignjatijevic, S. (2017): The Effects of Corruption on Innovation and Competitiveness: the Case of SEE Countries, Innovation, ICT and Education for the Next Generation. - Thematic Proceedings, Faculty of Economics and Engineering Management, Novi Sad: 135-153.

[4] Cornell University. (2017): INSEAD and WIPO, The Global Innovation Index 2017: Innovation Feeding the World, $10^{\text {th }}$ Edition. - Ithaca, Fontainebleau and Geneva.

[5] Crespo, N. F., Crespo, C. F. (2016): Global innovation index: Moving beyond the absolute value of ranking with a fuzzy-set analysis. - Journal of Business Research 69: 5265-5271.

[6] Dasic, M. (2014): Energy Safety of Southeast Europe Countries as a Regional Development Factor: Center for Economic and Financial Research. - Journal of Management, Law and Finance, Belgrade: 07/2014: 8-12.

[7] Djekic, I., Smigic, N., Glavan, R., Miocinovic, J., Tomasevic, I. (2018): Transportation sustainability index in dairy industry - Fuzzy logic approach. - Journal of Cleaner Production 180: 107-115. 
[8] Dual Citizen LLC. (2016): The Global Green Economy Index: Measuring National Performance in the Green Economy, $5^{\text {th }}$ Edition. - Washington, USA.

[9] Frank, A. G., Molle, N. D., Gerstlberg, W., Bernardi, J. A. B., Pedrini, D. C. (2016): An integrative environmental peroformance index for benchmarking in oil and gas industry. - Journal of Cleaner Production 133: 1190-1203.

[10] Hsu, A., Emerson, J., Levy, M., de Sherbinin, A.. Johnson, L., Malik, O., Schwartz, J., Jaiteh, M. (2014): The 2014 Environmental Performance Index. - Yale Center for Environmental Law \& Policy, New Haven, CT: www.epi.yale.edu.

[11] Kumar, P. (2017): Innovative tools and new metrics for inclusive green economy. Current Opinion in Environmental Sustainbility 24: 47-51.

[12] Latif, H., Gopalakrishnan, B., Nimbarte, A., Currie, K. (2017): Sustainability index development for manufacturing industry. - Sustainable Energy Technologies and Assessments 24: 82-95.

[13] Schlör, H., Venghaus, S., Hake, J-F. (2017): Green Economy Innovation Index (GEII) - a normative innovation approach for Germany \& its FEW Nexus. - Energy Procedia 142: 2310-2316.

[14] Shaker, R. R. (2018): A mega-index for the Americas and its underlying sustainable development correlations. - Ecological Indicators 89: 466-479.

[15] Van de Kerk, G., Manuel, A. R. (2008): A comprehensive index for a sustainable society: The SSI - the Sustainable Society Index. - Ecological Economics 66: 228-242.

[16] Vaninsky, A. (2018): Energy-environmental efficiency and optimal restructuring of the golabal economy. - Energy 153: 338-348.

[17] Wang, H., Ang, B. W. (2018): Assessing the role of international trade in global $\mathrm{CO}_{2}$ emissions: An index decomposition analysis approach. - Applied Energy 218: 146-158.

[18] Yale University. (2018): The 2018 Environmental Performance Index Report. - Center for Environmental Law \& Policy.

[19] Zugic, R. (2014): Macroeconomic Factors in the Development of the Transition Economies: Center for Economic and Financial Research. - Journal of Management, Law and Finance, Belgrade: 07/2014: 21-26.

[20] Zuo, X., Hua, H., Dong, Z., Hao, C. (2017): Environmental Performance Index at the Provincial Level for China 2006-2011. - Ecological Indicators 75: 48-56. 